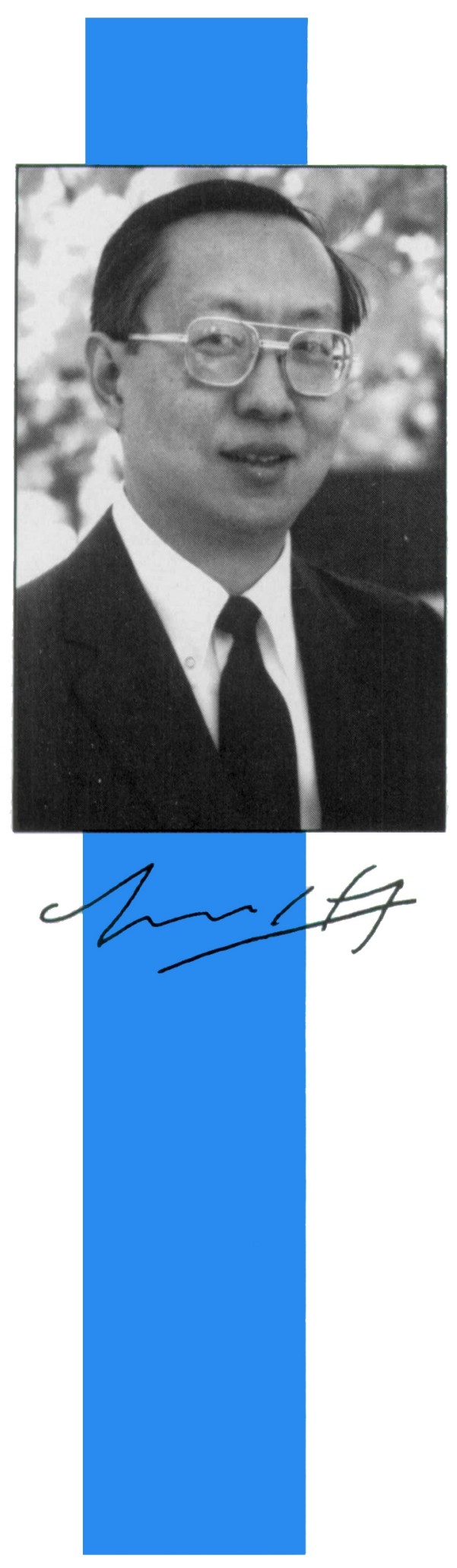

\title{
Update on Boston '89
}

Over the last 12 months more than 100 people, including volunteer organizers and MRS staff members, have been preparing what we believe will be one of the most exciting Boston meetings to date. Over 2,400 abstracts have already been received (as of July 18), and we are projecting a record attendance of over 4,000 people.

The meeting's main focus is the technical symposia organized by chairs Gary L. McVay of Pacific Northwest Laboratories, Robert J. Nemanich of North Carolina State University, and James C. Mikkelsen Jr. of Xerox. Following the traditions of interdisciplinary programming, the symposia will cover a very diverse materials area, ranging from electronic materials and polymers to nuclear waste and specialty cements. Oral presentations and posters will keep the attendees informed on the latest breakthroughs, allowing maximum interaction among the researchers.

The Society has invited Dr. Robert N. Noyce, a pioneer in the electronics industry and chief executive officer of Sematech, to present the Plenary Address on Monday evening, November 27. The traditional Von Hippel Award Ceremony will take place on Wednesday evening, November 29, together with the presentation of the Graduate Student Awards.

As a service to our membership and the materials community, MRS continues to sponsor short courses, equipment exhibits, and job placement services at our meetings. Many hours of work have been devoted to planning a meeting you won't want to miss. I look forward to meeting you in Boston.

\section{Inaugural Ceremonies for International Materials Research Committee}

During each of the past four Boston meetings a group of leaders representing interdisciplinary materials research societies worldwide has gotten together to discuss international cooperation in the advancement of materials research. Over the years, these meetings have grown larger, including representatives from many countries around the world. As a result of this group interaction, several international meetings have already taken place and plans for several future meetings are under way. The success of this initial cooperation has led the group to plan a formal organization-the International Materials Research Committee.

The founding members of the International Materials Research Committee include the Materials Research Society, the European Materials Research Society, the Joint Committee for Societies for Materials (Beijing), the Mexican Surface and Vacuum Science Society, the Chinese Society for Materials Science (Taiwan), the Advanced Materials Science and Engineering Society (Japan), the Materials Research Society-India, and the Australian Joint Materials Research Committee.

The International Committee has identified several main objectives:

1. To facilitate international cooperation among materials research organizations;

2. To contribute to the advancement of materials research in all its aspects;

3. To advance the multidisciplinary nature of materials research internationally;

4. To promote information exchange among national or regional societies with interests in interdisciplinary materials research, and to work to coordinate their activities;

5. To promote communication of international materials research activities through appropriate media; and

6. To encourage well-established materials research symposia to rotate through available meeting sites of materials research societies.

Inaugural ceremonies for the International Materials Research Committee will be held during the 1989 MRS Fall Meeting in Boston. All MRS members and meeting attendees are invited to attend this very special event.

R.P.H. Chang 